Check for updates

The BMJ

Cite this as: $B M J 2021 ; 375: \mathrm{n} 2718$ http://dx.doi.org/10.1136/bmi.n2718 Published: 08 November 2021

\section{Covid-19: Release of JCVI minutes prompts more questions over committee's decisions}

\author{
Elisabeth Mahase
}

The release of long delayed minutes from meetings of the UK government's vaccine advisory committee has raised more questions about its decision not to vaccinate all children aged 12 to 17 against SARS-CoV-2.

A raft of documents covering meetings in May, June, and July this year outline the Joint Committee on Vaccination and Immunisation's discussions of childhood vaccination and long covid in children. They show that in June the JCVI looked at modelling by the University of Warwick showing that if there were $80 \%$ covid vaccination coverage of 12-17 year olds there would be a "reduction in hospitalisations in all ages, with a substantial reduction in hospitalisations" and infections among 12 to 17 year olds after vaccination. The number of hospital admissions that could be avoided could reach 20 ooo, depending on public behaviour, the modelling showed.

Vaccinating children could also have benefits on children's mental health, it showed, especially in terms of "anxiety of getting covid-19 or long covid, both perceived and real, the anxiety of transmission to a vulnerable contact and the 'brain fog' described associated with covid-19."

But the JCVI said that most hospital admissions of children were likely to be among those with underlying illnesses, who could be targeted for selective vaccination. They also said that there may be "long-term benefits from natural infection in childhood" and that circulation of SARS-CoV-2 in children could "periodically boost immunity in adults through exposure.”

The committee announced at the beginning of September that it would not be recommending universal vaccination of 12-15 year olds because the margin of benefit, although in favour of vaccination, was considered too small. ${ }^{1}$ Instead it recommended vaccination just in children at risk of serious illness. At the time neither the minutes nor the data behind the decision were made public, and a freedom of information request for the minutes was rejected. ${ }^{2}$

The minutes are supposed to be made public within six weeks of a meeting, but there have been long delays throughout 2021. As at 5 November only minutes up to 29 July were available, and there seems to be a gap in March and April where no minutes have been published.

\section{Transparency issues}

Deepti Gurdasani, senior lecturer in epidemiology at Queen Mary University of London, told The BMJ, “I'm very concerned about the lack of transparency from JCVI . . . They still haven't released minutes from
August or September or the basis of their risk-benefit modelling analysis. Given the critical importance of the decisions being made, and the fact that the UK is an outlier across most of the globe, we need much clearer and more transparent and timely messaging from the JCVI to maintain public trust in their advice."

In some countries, such as the US and Israel, children as young as 5 years old have begun to be vaccinated against covid-19. 34

Gurdasani, a member of the Independent Scientific and Advisory Group for Emergencies, which has long been calling for the JCVI to be more transparent to the public, said, "There are real worries about the decisions that have been made by JCVI. There is a lot of inconsistency in their stated scope, and a tendency to overweight potentially unknown long term risks from vaccination, while minimising the risk of covid-19 to children, despite the risk from SARS-CoV-2 being greater than that of many childhood illnesses."

Responding to the committee's message that natural immunity from infection in children might be advantageous, she said, "These narratives are unevidenced and unethical. The idea that it's OK to expose children to a novel neurotropic virus that causes multisystem disease when they could be vaccinated and protected is, frankly, bizarre.”

Despite the JCVI's decision not to recommend universal vaccination in 12-15 year olds, the government later (13 September) accepted the UK chief medical officers' recommendation to vaccinate all children in this age group, on the basis of an assessment that included transmission in schools and the effect on children's education.

A JCVI spokesperson said it was committed to transparency and would publish all meeting minutes in due course but added that these were not intended as "messaging" and should not be read in isolation of the associated statements.

The spokesperson also noted that vaccines did not completely eliminate the risk of transmission and that therefore it was likely that many young children, in whom SARS-CoV-2 generally causes mild disease, would gain immunity from natural infection.

lacobucci G. Covid-19: JCVI opts not to recommend universal vaccination of 12-15 year olds. BMJ 2021;374:n2180.

doi: 10.1136/bmj.n2180 pmid: 34479872

2 Mahase E. Covid-19: Vaccine advisory committee must be more transparent about decisions, say researchers. BM/2021;375:n2452. doi: 10.1136/bmi.n2452 pmid: 34620583

3 Borter G, O'Donnell C. US rolls out covid-19 vaccine for young children, ending long wait for some parents. Reuters. 4 Nov 2021.

https://www.reuters.com/world/us/us-start-giving-covid-19-vaccines-youngchildren-2021-11-03.

4 Spiro A. After FDA nod, Israel gears up to start vaccinating 5- to 11-year-olds. Times Isr2021;8. https://www.timesofisrael.com/pm-bennett-to-conveneadvisers-on-vaccinating-5-to-11-year-olds. 
This article is made freely available for use in accordance with BMI's website terms and conditions for the duration of the covid-19 pandemic or until otherwise determined by BMJ. You may use, download and print the article for any lawful, non-commercial purpose (including text and data mining) provided

that all copyright notices and trade marks are retained. 